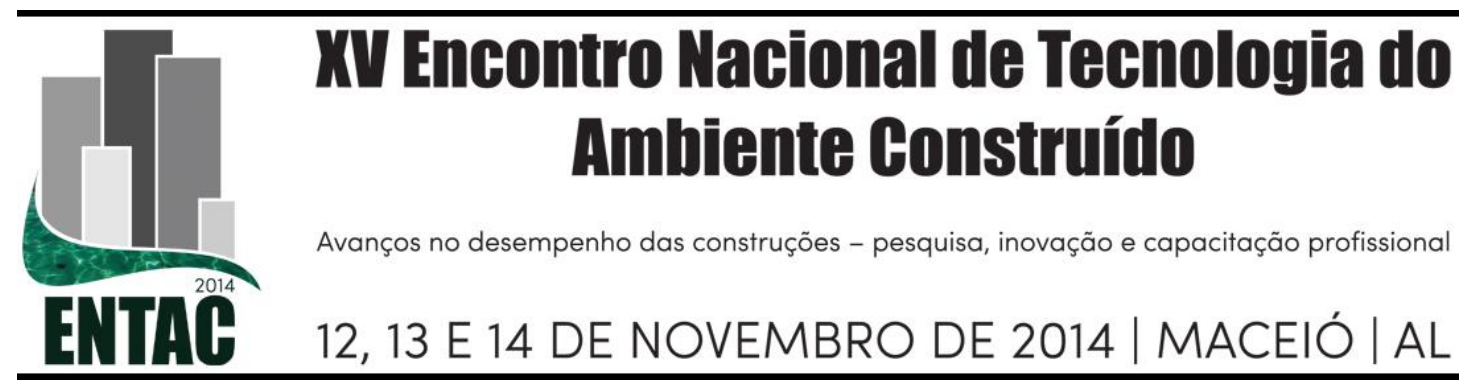

\title{
ATMOSFERA DO PONTO DE VENDA: RECOMENDAÇÕES PROJETUAIS PARA JOALHERIAS
}

\author{
BINS ELY, Vera Helena Moro (1); NOEBAUER, Marlise Paim Braga (2); \\ CARRILHO, André (3).
}

(1) UFSC, e-mail: vera.binsely@gmail.com (2) UFSC, e-mail: arquiteta@lisenoebauer.arq.br, (3) UFSC, e-mail: carrilho.and@gmail.com.

\begin{abstract}
RESUMO
O comércio varejista atravessa uma revolução: o cliente quer viver boas experiências de compra e os ambientes comerciais refletem esta realidade. Inúmeras pesquisas realizadas sobre o tema visam bem atender o possível comprador. Principalmente focadas na produtividade, são efetuadas avaliações da atmosfera do ponto de venda e dos seus atributos: layout, formas, materiais, estilo, iluminação, esquemas tonais, som, aromas e texturas. Em menor número são os estudos focados nas pessoas que trabalham no varejo. O presente artigo aborda o contexto da atmosfera do ponto de venda, deslocando o eixo usual dos usuários clientes em potencial, para os usuários funcionários do ciclo de vendas, quais sejam: gerente, vendedores e caixa. O objetivo desse trabalho é a avaliação da atmosfera de uma joalheria, buscando atender as necessidades dos profissionais do ciclo de vendas, qualificando sua rotina laboral e produtividade e apontando recomendações para projetos futuros nesta área. O estudo de caso, voltado ao ambiente construído, com ênfase na distribuição do layout, nos aspectos lumínicos e na especificação dos materiais e acabamentos, apresenta resultados parciais da pesquisa de caráter exploratório. A abordagem multimetodológica utilizou: visitas exploratórias, pesquisas documental e bibliográfica, observações assistemáticas, entrevistas semi-estruturadas, walkthrough e análise antropométrica. Os resultados dessa APO permitiram propor intervenções para melhoria do ambiente estudado e recomendações projetuais para estabelecimentos varejistas do mesmo setor.
\end{abstract}

Palavras-chave: Atmosfera, Avaliação Pós-Ocupação, Ambiência

\begin{abstract}
The retail commerce passes through a revolution, in which the client wants to have good shopping experiences and the commercial environments reflect this reality. Numerous studies carried out on the subject aim at well meet the possible buyer. Focusing on productivity, evaluations are performed on the atmosphere of the place of sale and its attributes: layout, shapes, materials, style, lighting, tonal schemes, sound, scents and textures. Fewer studies are focused on the people who work in retail stores. The present article deals with the context of the atmosphere in retail stores, displacing the usual shaft from the users that are potential customers to those users who are employees of the sales cycle, which are: manager, salespeople and cashiers. The purpose of this work is the evaluation of the atmosphere of a jewelry store, aiming at meeting the needs of professionals in the sales cycle, qualifying their labor routine and productivity and indicating recommendations for future projects in this area. The case study, addressed to the built environment, with emphasis on layout distribution, lighting aspects, specification of materials and finishing, presents partial results of this exploratory character research. The multimethodological approach used: exploratory visits, documentary and bibliographic research, unsystematic observation, semi-structured interviews, walkthrough and anthropometric analysis. The results of this POE allowed it to propose interventions for improvement of the studied environment and project recommendations for retail establishments in the same industry.
\end{abstract}

Keywords: Atmosphere, Post-Occupancy Evaluation (POE), Ambience. 


\section{INTRODUÇÃO}

Atualmente, o projeto de ambientes comerciais se mostra mais reconhecidamente complexo e de importância estratégica, pois precisa oferecer respostas adequadas às mudanças ocorridas no universo varejista. Deve corresponder às exigências de flexibilidade, adaptação ao modelo organizacional e imagem da empresa, das relações de trabalho, do conforto, segurança e qualidade de vida dos usuários - clientes e funcionários - e de respeito ambiental.

Quanto mais elevado o nível socioeconômico do público-alvo de determinado nicho de mercado varejista, mais altos e complexos são os investimentos. Joalherias fazem parte de um seleto mercado, suas lojas pressupõem cuidados que coloquem o ponto de venda e sua atmosfera condizente com seu mix de produtos e no nível do público que deseja atingir. Assim como existe uma lacuna no que tange a trabalhos voltados às necessidades dos funcionários dos pontos de venda, há também uma disparidade no direcionamento dos investimentos realizados, no sentido de atender, de forma equilibrada, as necessidades de clientes e funcionários. A balança pende para $\mathrm{o}$ atendimento dos compradores em potencial.

A seleção do objeto de estudo atendeu a alguns critérios de pesquisa: (1) deveria ser um negócio local, sólido, com investimentos regulares no crescimento de sua marca e fixação no mercado, em especial no tocante à qualificação de seus pontos de venda; (2) deveria ser situada em local de grande fluxo de pessoas, pressupondo muitos atendimentos e bom fluxo de vendas; (3) quantidade significativa de funcionários, possibilitando um bom número de entrevistados, apoiando os resultados. A pesquisa foi realizada em uma unidade recém reformada de uma rede de joalherias, localizada em uma rua de pedestres, em centro urbano. A escolha do tipo de loja a ser avaliada e o foco nos funcionários visou incentivar uma melhor distribuição dos investimentos do setor, melhorando não apenas a experiência de compra dos clientes, mas a vida dos funcionários. O objetivo é produzir diretrizes que contribuam para qualificar as demais lojas da rede estudada e referenciem futuros projetos de joalherias. A Figura 1 apresenta o ambiente estudado. E a Tabela 1, a caracterização da amostra.

Figura 1: Caracterização do ambiente.

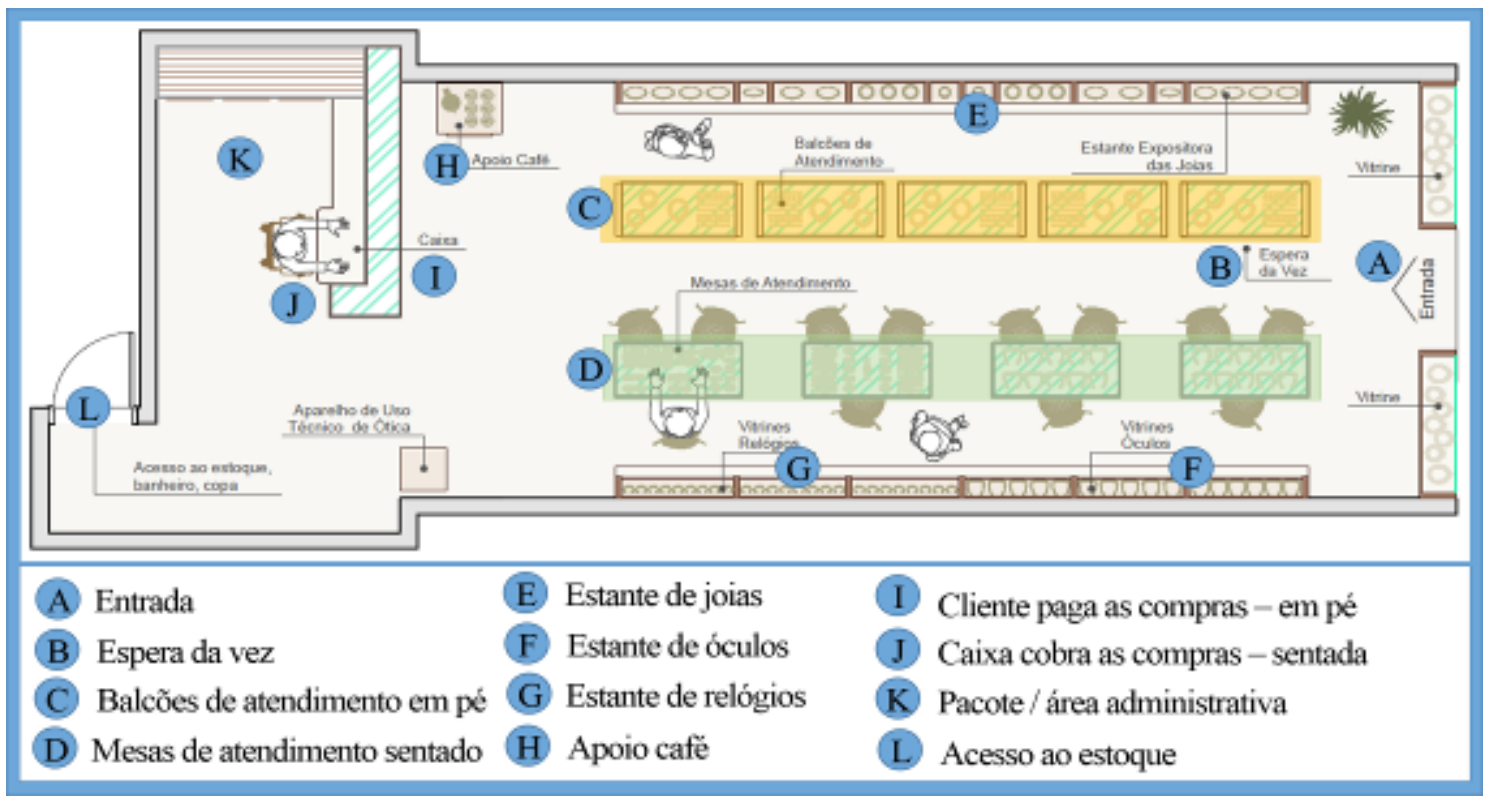

Fonte: Pesquisadores. 
Tabela 1: Caracterização da Amostra.

\begin{tabular}{|c|c|c|c|c|c|c|}
\hline CARGO & IDADE & ESTATURA & $\begin{array}{l}\text { EXERCÍCIO } \\
\text { FÍSICO }\end{array}$ & $\begin{array}{l}\text { TEMPO DE } \\
\text { SERVIÇO BT }\end{array}$ & & $\begin{array}{l}\text { XPERIÊNCIA } \\
\text { ANTERIOR }\end{array}$ \\
\hline Gerente & 37 & $1,53 \mathrm{~m}$ & 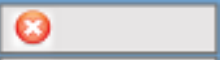 & 1 ano e 5 meses & $(0$ & 6 anos e 6 meses \\
\hline Vendedora 1 & 57 & $1,64 \mathrm{~m}$ & (7) $3 x /$ sem & 1 ano e 3 meses & 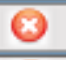 & \\
\hline Vendedora 2 & 27 & $1,50 \mathrm{~m}$ & (2) & 3 anos & 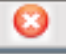 & \\
\hline Vendedora 3 & 25 & $1,56 \mathrm{~m}$ & $\mathbf{X}$ & 4 meses & 8 & 2 anos \\
\hline Vendedora 4 & 34 & $1,64 \mathrm{~m}$ & $\otimes$ & 3 anos e 6 meses & 0 & 1 ano e 3 meses \\
\hline Vendedora 5 & 30 & $1,59 \mathrm{~m}$ & $\mathcal{X}$ & 9 meses & 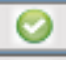 & 3 meses \\
\hline Caixa & 30 & $1,60 \mathrm{~m}$ & $\mathbf{2}$ & 3,5 meses & $\theta$ & 9 meses \\
\hline
\end{tabular}

Fonte: Pesquisadores.

\section{REFERENCIAL TEÓRICO}

A avaliação da atmosfera do ponto de venda buscou o aporte científico da Ergonomia e da Psicologia Ambiental. Estas áreas do conhecimento se complementam, trazendo à luz inúmeros conhecimentos sobre as interações humanas e a tecnologia, a organização e o ambiente, bem como sobre o comportamento decorrente dessa correlação.

Conforme Moraes e Mont'alvão (2003), ergonomia é o estudo das relações do homem com seu ambiente ao realizar qualquer tipo de tarefa, seja de trabalho, de lazer e atividades do dia-a-dia. A Psicologia Ambiental é uma área de estudos interdisciplinar na qual o homem não é visto como agente passivo dentro do ambiente no qual vive, mas como ator que interage ciclicamente com o ambiente. Segundo Okamoto (2002), as percepções decorrentes das sensações, acrescidas de outros estímulos externos, intervém e conduzem o comportamento. Assim, o comportamento é resultado da interação entre o indivíduo e os estímulos recebidos do ambiente onde se insere e depende da percepção que cada indivíduo tem de determinado espaço e como dele se apropria.

Conceituada inicialmente por Kotler (1973-1974, p.50), a atmosfera do ponto de venda é, segundo o autor: “(...) o planejamento consciente do espaço com o intuito de criar efeitos emocionais específicos em compradores e, consequentemente, aumentar a probabilidade de compra". Atmosfera é, portanto, uma experiência completa, envolvida por vários fatores, como atendimento, propaganda, embalagem e o ambiente.

Baker et al (2002) propõe três categorias que compõem a atmosfera. Fatores de Projeto: características visuais que subdividem-se em duas áreas: funcionais e estéticas. Fatores ambientais: relativos às sensações captadas pelos demais sentidos, como temperatura, iluminação, som, odores e perfumes. Fatores sociais: relativos ao atendimento, como número de profissionais existentes na loja, apresentação pessoal e cortesia. Para este estudo foram utilizados os conceitos relativos aos fatores ambientais e de projeto.

\section{MÉTODOS}

Esta pesquisa foi desenvolvida na disciplina de Avaliação do Ambiente Construído com Foco no Usuário, do Programa de Pós-Graduação em Arquitetura e Urbanismo PósARQ - da Universidade Federal de Santa Catarina - UFSC. De caráter exploratório, o estudo de caso aplicou e relacionou multimétodos de abordagem ergonômica e das pesquisas em Avaliação Pós-Ocupação. Segundo Rheingantz (2000), a Avaliação PósOcupação - APO - é uma vertente metodológica interdisciplinar utilizada para avaliar o desempenho do ambiente construído em uso, segundo a ótica de seus usuários. Foram 
avaliados a atmosfera do ponto de venda, a percepção e o comportamento dos indivíduos em seu ambiente de trabalho. A abordagem ergonômica foi embasada no modelo apresentado por Guérin et al. (2001), caracterizado pela flexibilidade procedimental, pela evolução das etapas e que pressupõe a participação voluntária dos sujeitos envolvidos e investigação do trabalho nas situações reais onde este se inscreve. A Tabela 2 relaciona métodos, objetivos e procedimentos experimentais da pesquisa.

Tabela 2: Síntese metodológica, objetivos e experimentos correspondentes.

\begin{tabular}{|c|c|c|c|}
\hline \multicolumn{2}{|c|}{ MÉTODO / TÉCNICA } & OBJETIVO & EXPERIMENTOS \\
\hline \multicolumn{2}{|c|}{ Visitas Exploratórias } & $\begin{array}{l}\text { Caracterizar o ambiente em seus atributos e } \\
\text { dimensões. }\end{array}$ & $\begin{array}{c}04 \text { Visitas Exploratórias: realizados os } \\
\text { levantamentos fotográfico e dimensional e a } \\
\text { análise do ambiente. }\end{array}$ \\
\hline \multicolumn{2}{|c|}{$\begin{array}{c}\text { Pesquisas Documental e } \\
\text { Bibliográfica }\end{array}$} & $\begin{array}{l}\text { Compreender as normativas das profissões } \\
\text { estudadas, ter acesso ao projeto de interiores da } \\
\text { loja, ou da loja conceito da rede. Construção do } \\
\text { aporte teórico, nas áreas de projetos } \\
\text { comerciais, ergonomia e psicologia ambiental. }\end{array}$ & $\begin{array}{l}\text { Pesquisa dos dados das profissões em estudo } \\
\text { junto à Classificação Brasileira de Ocupações } \\
\text { (CBO). Busca junto à administração da rede, } \\
\text { do projeto de interiores da loja. Leitura e } \\
\text { pesquisa em livros, artigos. }\end{array}$ \\
\hline \multicolumn{2}{|c|}{ Observação Sistemática } & $\begin{array}{l}\text { Avaliar o comportamento dos usuários no } \\
\text { espaço, compreender as atividades por eles } \\
\text { executadas. }\end{array}$ & $\begin{array}{l}\text { Observação da relação usuários/ambiente na } \\
\text { utilização de } 04 \text { postos de trabalho. Anotações } \\
\text { sistemáticas em instrumento prévio (planta } \\
\text { baixa da loja). }\end{array}$ \\
\hline \multirow{3}{*}{$\begin{array}{c}\text { Entrevistas } \\
\text { Semiestruturadas }\end{array}$} & Proprietário & $\begin{array}{c}\text { Conhecer a história da empresa e seu sistema } \\
\text { organizacional e hierárquico }\end{array}$ & $\begin{array}{l}\text { Entrevista com perguntas previamente } \\
\text { elaboradas, enriquecida de informações } \\
\text { durante seu decorrer. }\end{array}$ \\
\hline & Gerente & $\begin{array}{c}\text { Compreender a hierarquia desta unidade da rede, } \\
\text { as rotinas da equipe e as tarefas prescritas de } \\
\text { cada funcionária. }\end{array}$ & $\begin{array}{l}\text { Entrevista previamente elaborada, acrescida } \\
\text { de outras informações durante o seu } \\
\text { decorrer. }\end{array}$ \\
\hline & $\begin{array}{l}\text { Vendedoras } \\
\text { e Caixa }\end{array}$ & $\begin{array}{l}\text { Conhecer o comportamento e a percepção das } \\
\text { funcionárias, coletar dados para avaliação } \\
\text { antropométrica. }\end{array}$ & $\begin{array}{c}\text { Entrevista sobre a rotina laboral, sobre as } \\
\text { tarefas prescritas e sobre dados físicos de } \\
\text { cada funcionária. }\end{array}$ \\
\hline \multirow{2}{*}{ Walkthrough } & Gerente & $\begin{array}{l}\text { Captar as impressões da gerente sobre cada } \\
\text { espaço percorrido. }\end{array}$ & $\begin{array}{l}\text { Observação e registro em planta baixa: } \\
\text { impressões da gerente ao apresentar cada } \\
\text { ambiente percorrido. }\end{array}$ \\
\hline & Vendedora 4 & $\begin{array}{l}\text { Captar as impressões da vendedora } 4 \text { sobre } \\
\text { cada espaço percorrido. }\end{array}$ & $\begin{array}{c}\text { Observação e registro em planta baixa: } \\
\text { impressões da vendedora 4, na apresentação } \\
\text { dos ambientes. }\end{array}$ \\
\hline
\end{tabular}

Fonte: Pesquisadores.

\section{RESULTADOS E DISCUSSÃO}

Os métodos utilizados foram pródigos em seus resultados, colaborando no sentido da contextualização da área em estudo e compreensão do ambiente, bem como das rotinas e tarefas realizadas. O corpo funcional é composto por 8 funcionários, o técnico de ótica, que por não participar do ciclo de vendas não participa da amostra, e 1 gerente, 5 vendedoras e 1 caixa, já caracterizados na introdução, na Tabela 1.

A joalheria funciona em horário comercial, sem intervalo para almoço, em dois turnos que se sobrepõem no período de maior movimento, o vespertino. A abertura da loja ocorre às $8: 30 \mathrm{~h}, 30$ minutos antes do atendimento ao púbico iniciar, e fecha as portas às 19:30h, 30 minutos depois de encerrado o atendimento, conforme ilustra a Figura 2.

Figura 2: Organização dos Turnos de Trabalho.

\begin{tabular}{|c|c|c|c|c|c|}
\hline \multicolumn{6}{|c|}{ TURNOS DOS FUNCIONÁRIOS } \\
\hline $08: 30$ & 09:00 & $10: 00$ & $18: 00$ & 19:00 & $19: 30$ \\
\hline \multicolumn{6}{|c|}{ Vendedora 1} \\
\hline & & \multicolumn{4}{|c|}{ Vendedoras $2,3,4$ e 5 e caixa } \\
\hline \multicolumn{6}{|c|}{ Gerente } \\
\hline & \multicolumn{5}{|c|}{ Sobreposição de todos os turnos } \\
\hline
\end{tabular}

Fonte: Pesquisadores. 
As funcionárias têm uma hora de almoço e dois intervalos diários de 15 minutos. Estes horários são frequentemente utilizados para tratar de assuntos pessoais além do descanso e alimentação, e não raro, as funcionárias preferem voltar à pista de atendimento, visando otimizar suas vendas, ao invés de descansar.

O estudo proporcionou o entendimento das atividades laborais de gerente, vendedoras e caixa, reais (relatadas e observadas) que, em comparação com as tarefas prescritas pela gerente, responsável pelas contratações, se mostraram coincidentes. Estes dados foram comparados às tarefas determinadas pela Classificação Brasileira de Ocupações, para a profissão de gerente (CBO-1423-5), de vendedor (CBO-5211-10) e de caixa (CBO4211-25). A Figura 3 apresenta as atividades da gerente, das vendedoras e da caixa, marcando, em vermelho, as que vão além das tarefas determinadas pela CBO.

Figura 3: Atividades Reais=Prescritas da Gerente.

\begin{tabular}{|c|c|c|c|c|c|c|c|c|c|c|c|}
\hline \multicolumn{12}{|c|}{ GERENTE } \\
\hline \begin{tabular}{l||l} 
Abrir & $\mathrm{L}$ \\
a loja & $\mathrm{d}$
\end{tabular} & $\begin{array}{l}\text { Limpeza } \\
\text { das joias }\end{array}$ & \multicolumn{2}{|c|}{$\begin{array}{c}\text { Contagem } \\
\text { das joias } \\
\end{array}$} & \multicolumn{2}{|c|}{$\begin{array}{l}\text { Atender } \\
\text { clientes }\end{array}$} & \multicolumn{3}{|c|}{$\begin{array}{l}\text { Selecionar, treinar e } \\
\text { administrar a equipe }\end{array}$} & \multicolumn{2}{|c|}{$\begin{array}{c}\text { Fazer } \\
\text { café }\end{array}$} & $\begin{array}{c}\text { Buscar mercadorias } \\
\text { em outra loja }\end{array}$ \\
\hline \multicolumn{3}{|c|}{$\begin{array}{l}\text { Promover segurança, saúde, } \\
\text { ambiente de qualidade }\end{array}$} & \multicolumn{2}{|c|}{$\begin{array}{c}\text { Gerenciar } \\
\text { recursos }\end{array}$} & \multicolumn{3}{|c|}{\begin{tabular}{|l|} 
Assessorar a diretoria \\
e setores da empresa
\end{tabular}} & \multicolumn{2}{|c|}{$\begin{array}{c}\text { Fechar } \\
\text { a loja }\end{array}$} & \multicolumn{2}{|c|}{$\begin{array}{c}\text { Levar a receita do } \\
\text { dia para a loja matriz }\end{array}$} \\
\hline \multicolumn{12}{|c|}{ VENDEDORAS } \\
\hline $\begin{array}{l}\text { Limpeza } \\
\text { das joias }\end{array}$ & \multicolumn{2}{|c|}{$\begin{array}{l}\text { Contagem } \\
\text { das joias }\end{array}$} & \multicolumn{4}{|c|}{\begin{tabular}{||c||} 
Vender, auxiliando \\
os clientes na escolha
\end{tabular}} & \multicolumn{4}{|c|}{$\begin{array}{l}\text { Demonstrar os produtos } \\
\text { e seu funcionamento }\end{array}$} & $\begin{array}{l}\text { Organizar os produtc } \\
\text { de maneira atrativa }\end{array}$ \\
\hline \multicolumn{2}{|c|}{$\begin{array}{l}\text { Informar a qualidade e } \\
\text { vantagens dos produtos }\end{array}$} & \multicolumn{4}{|c|}{$\begin{array}{c}\begin{array}{c}\text { Buscar mercadorias } \\
\text { em outra loja }\end{array} \\
\end{array}$} & \multicolumn{4}{|c|}{\begin{tabular}{|c|} 
Fazer relatórios de vendas \\
e pesquisas de preços
\end{tabular}} & \multicolumn{2}{|c|}{$\begin{array}{l}\text { Efetuar as trocas } \\
\text { para os clientes }\end{array}$} \\
\hline \multicolumn{12}{|c|}{ CAIXA } \\
\hline $\begin{array}{l}\text { Limpeza } \\
\text { das joias }\end{array}$ & \multicolumn{3}{|c|}{\begin{tabular}{|} 
Usar 2 sistemas \\
de conferência e \\
prestar contas
\end{tabular}} & $\begin{array}{l}\text { Cobra } \\
\text { venda: }\end{array}$ & \multicolumn{2}{|c|}{\begin{tabular}{|c|} 
Informar e \\
orientar o \\
público
\end{tabular}} & \begin{tabular}{l|} 
Checar \\
e-mails
\end{tabular} & \multicolumn{3}{|c|}{\begin{tabular}{|c|} 
Prestar \\
relatórios \\
administrativos
\end{tabular}} & \begin{tabular}{|c|}
$\begin{array}{c}\text { Levar a receita } \\
\text { do dia para a } \\
\text { loja matriz }\end{array}$ \\
\end{tabular} \\
\hline
\end{tabular}

Fonte: Pesquisadores.

As entrevistas foram de especial ajuda na compreensão da percepção ambiental dos usuários. Suas impressões foram relacionadas de acordo com a categorização proposta por Baker et al (2002), citada na fundamentação teórica e, estão dispostas na Tabela 3.

Tabela 3: Atributos do ambiente da loja e impressões dos funcionários.

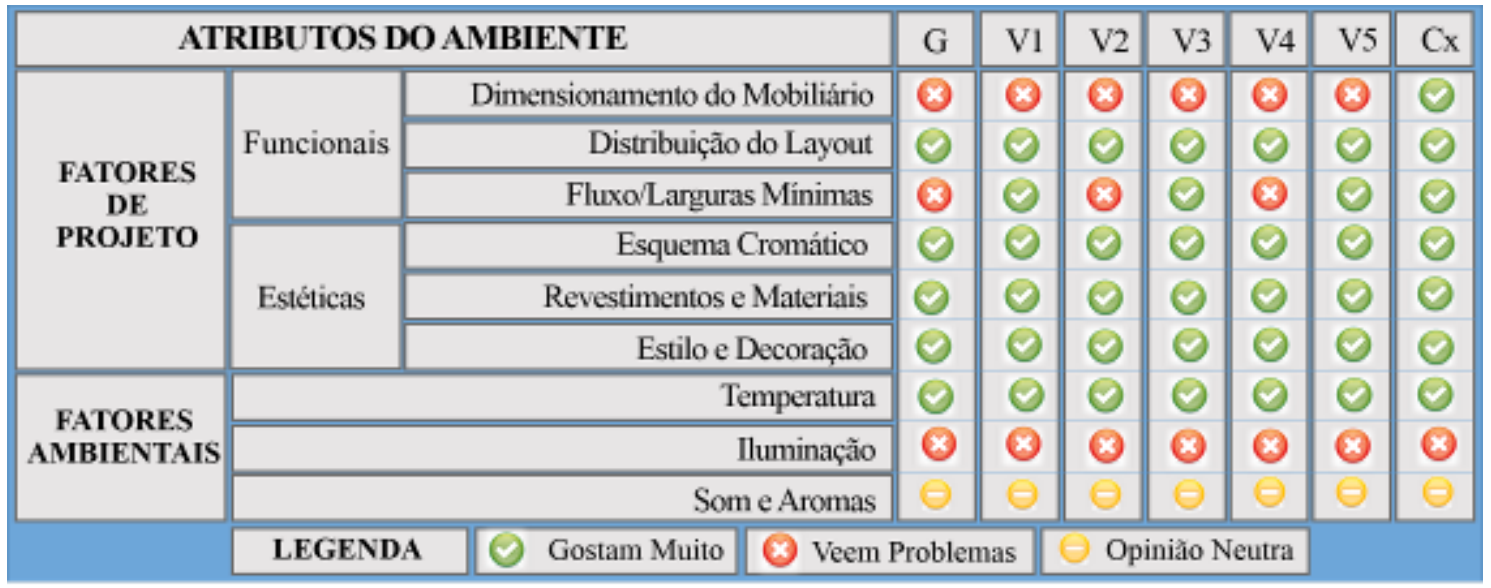

Fonte: Pesquisadores. 
Foram analisadas as atividades em quatro postos de trabalho, conforme indicados na Figura 4. Todas, exceto a caixa, trabalham sem um posto fixo de trabalho. As mesas, que também são expositores, são utilizadas em rodízio por todas as vendedoras. A falta de um posto fixo parece, a todas, algo natural da atividade de vendas e não há descontentamento em relação a este fato. A caixa se mostrou muito satisfeita com seu posto de trabalho, pois está, a seu ver, bem dimensionado.

Figura 4: Planta baixa da loja, com marcação dos postos de trabalho avaliados.

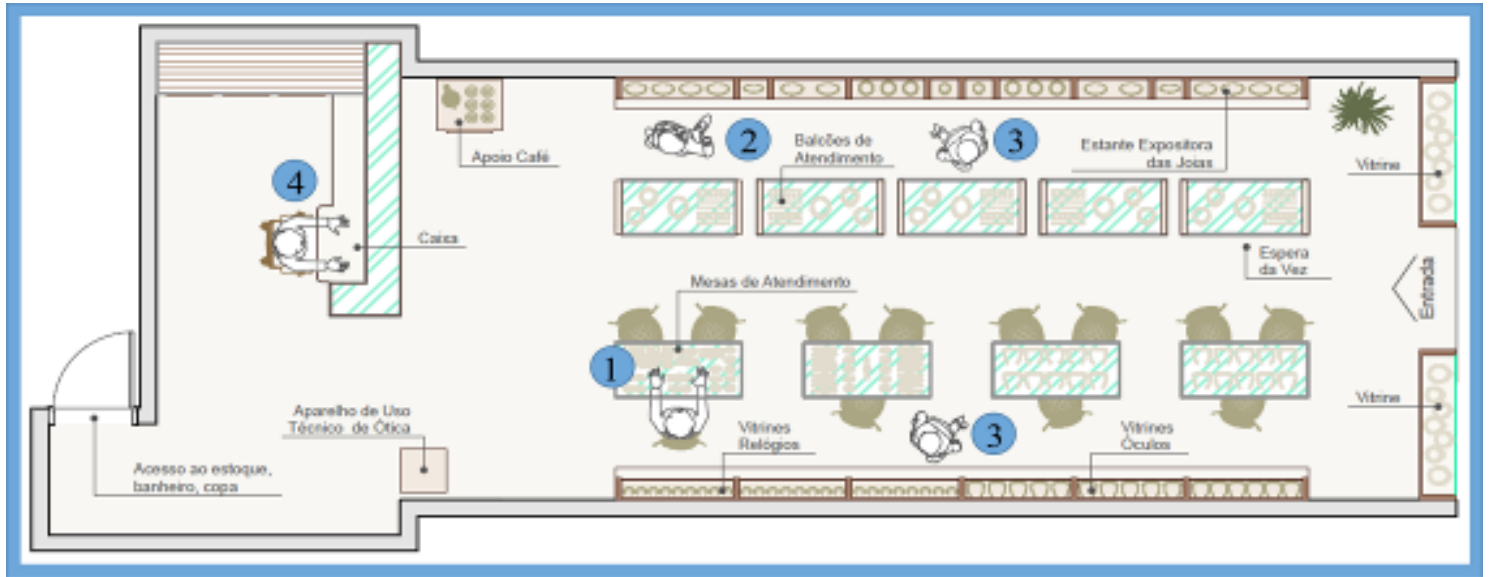

1) Receber o cliente nas mesas de atendimento;

(2) Pegar peças dispostas nos nichos das estantes;

3 Manusear peças nas gavetas das estantes e balcões;

(4) Receber o pagamento no caixa.

Fonte: Pesquisadores.

Desenvolveu-se uma simulação gráfica digital com manequins, representando posturas nos postos de trabalho. Utilizaram-se modelos correspondentes aos percentis extremos da amostra: a vendedora 2, com altura igual a 1,50m, e as vendedoras 1 e 4, com altura igual a 1,64m. A avaliação comparou as simulações com parâmetros oferecidos por Panero e Zelnik (2010).

Os postos de trabalho 1 e 4 são utilizados na posição sentada. Segundo os autores, para referência de medidas relativas ao alcance como fator determinante, deve-se utilizar os dados de pessoas com menores dimensões corporais. Quando o fator determinante é o espaço livre, a referência a ser utilizada deve ser a de pessoas maiores. Na posição sentada, as medidas relevantes a serem consideradas para uma boa relação mesacadeira, estão indicadas na figura 5. As menores medidas se referem a padrões de conforto para atender o percentil 5 da população feminina, que no Brasil é de $1,51 \mathrm{~m}$, e as medidas maiores, para atender o outro extremo da população, o percentil 95 do homem brasileiro, que é igual a $1,84 \mathrm{~m}$.

Figura 5: Referências ergonômicas para os postos de trabalho.
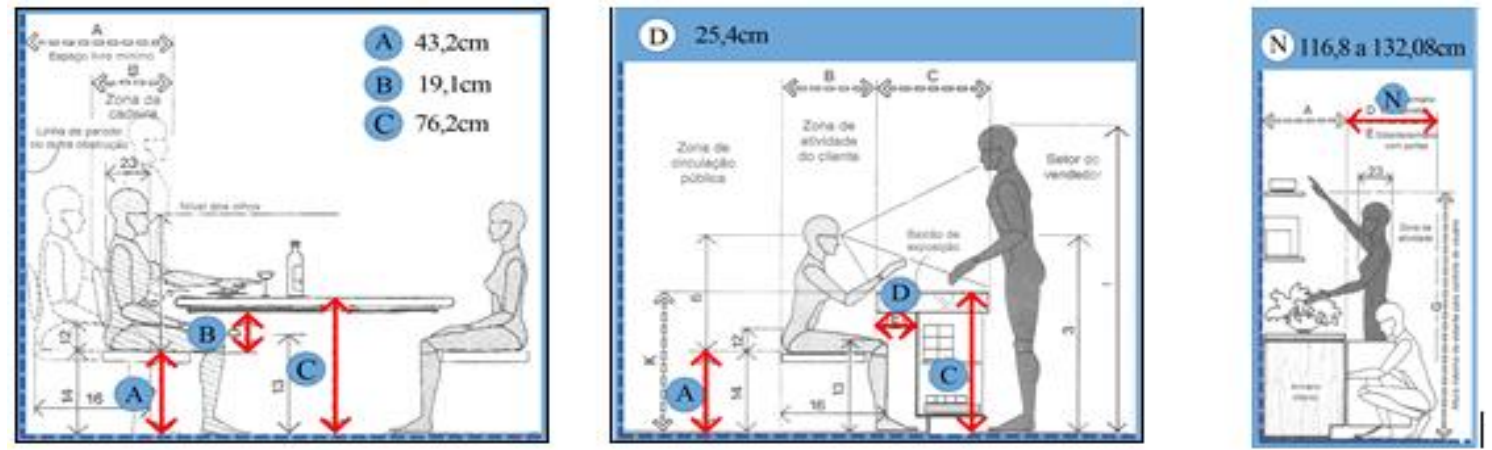

Fonte: Panero e Zelnik (2010). Adaptação gráfica dos pesquisadores. 
Figuras 6, 7 e 8: indicam a realidade dos postos de trabalho.

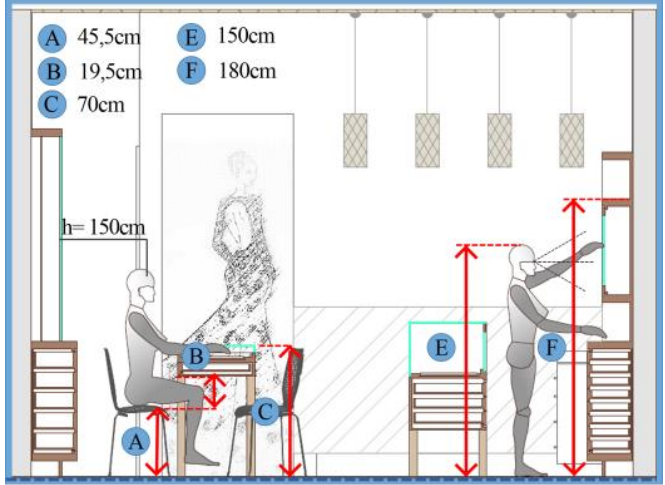

Posto de Trabalho 1

Posto de Trabalho 2

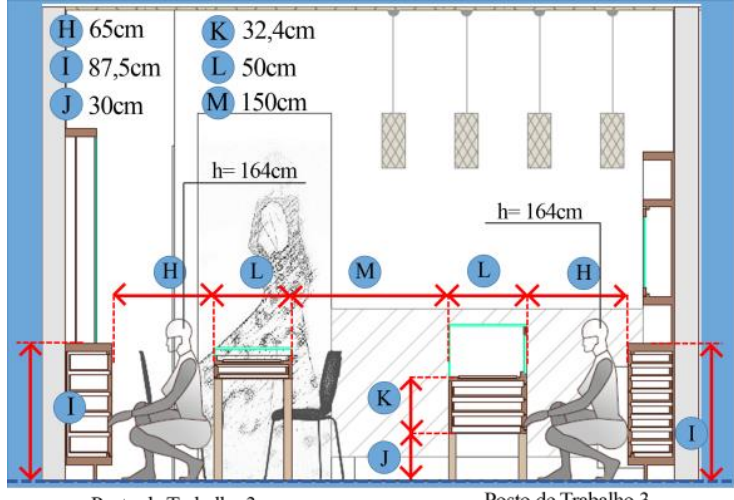

Posto de Trabalho 3

Posto de Trabalho 3

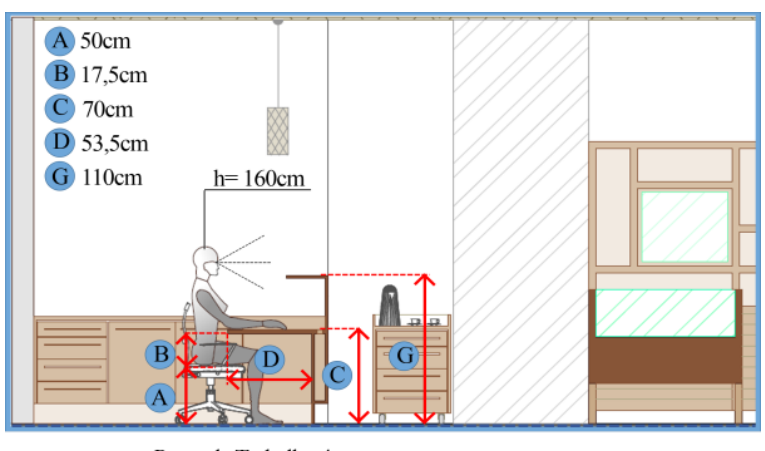

Posto de Trabalho 4

Fonte: Pesquisadores.

Posto de Trabalho 1 (Figuras 6 e 9): A simulação confirmou que a maioria das vendedoras e a gerente têm dificuldade no atendimento no posto 1 , em função do desconforto da altura da cadeira e desproporção da relação mesa-cadeira. Para o conforto da vendedora de menor estatura, a altura da cadeira deveria ser de $35,60 \mathrm{~cm}$, segundo as tabelas propostas por Panero e Zelnik (2010). Contudo, para bem atender a vendedora mais alta, a cadeira deveria ser de $48,40 \mathrm{~cm}$. Notadamente, este intervalo é muito grande e os autores mesmo respondem a este dilema, indicando que cadeiras de trabalho com $43,20 \mathrm{~cm}$ devem atender a maior parte dos adultos e que, eventualmente, pessoas de baixa estatura que não se sentirem confortáveis, poderão acomodar-se melhor com um pequeno apoio para os pés. Na relação mesa-cadeira, o indicado é que a mesa, para a altura de cadeira especificada em $43,20 \mathrm{~cm}$, tenha uma altura entre $73,70 \mathrm{e}$ $76,20 \mathrm{~cm}$. As mesas atuais, com altura igual a $85,50 \mathrm{~cm}$, fogem em muito a este padrão.

\section{Figuras 9: indica a realidade dos postos de trabalho 1 e 2.}
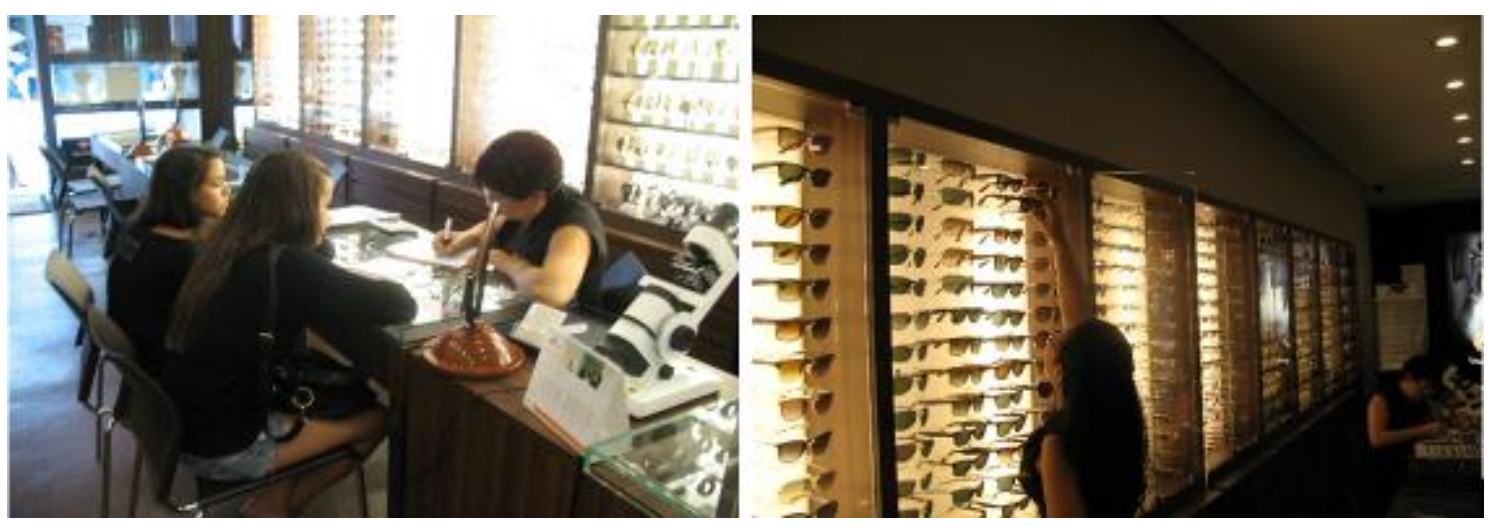

Fonte: Pesquisadores. 
Posto de Trabalho 2 (Figuras 6 e 9): A maioria das vendedoras e a gerente têm dificuldade de alcance no posto 2 , em função da altura elevada dos nichos superiores. As vendedoras 1 e 4, com altura igual a 1,64m, não encontram problema em alcançar os nichos, cuja base dista $1,80 \mathrm{~m}$ do piso, quando o indicado é a altura máxima de $1,67 \mathrm{~m}$ para prateleiras a serem usadas por pessoas do sexo feminino, conforme demonstrado na Figura 6 que retrata os postos de trabalho 1 e 2 . Os modelos são relativos à Vendedora 2 , de menor estatura $(\mathrm{h}=1,50 \mathrm{~m})$. Fica claro o seu constrangimento postural no posto de trabalho 1. A funcionária não consegue apoiar os pés no chão, nem os braços na mesa de atendimento.

Posto de Trabalho 3 (Figuras 7 e 10): consiste em pegar objetos nas gavetas inferiores, dispostas em ambos os lados da loja. A medida mínima recomendada para a largura de corredor quando se trata do acesso às portas e gavetas dispostas em locais altos e baixos, é de $116,8 \mathrm{~cm}$, conforme indicado na Figura 5, terceira parte. A Figura 7 expõe a simulação, com o corredor entre balcões e estante de joias, com $65 \mathrm{~cm}$ de largura, bem aquém da medida confortável. Do ponto de vista da utilização das cadeiras, o corredor entre mesas de atendimento e estante de óculos e relógios é crítico, pois é necessária uma largura de 45,70 a $61 \mathrm{~cm}$ para a utilização de cadeira, sem considerar uma pessoa passando por trás de uma pessoa sentada, levando-se em conta os percentis 5 e 95 da população brasileira do sexo feminino.

Figuras 10: indica a realidade dos postos de trabalho 1 e 2.
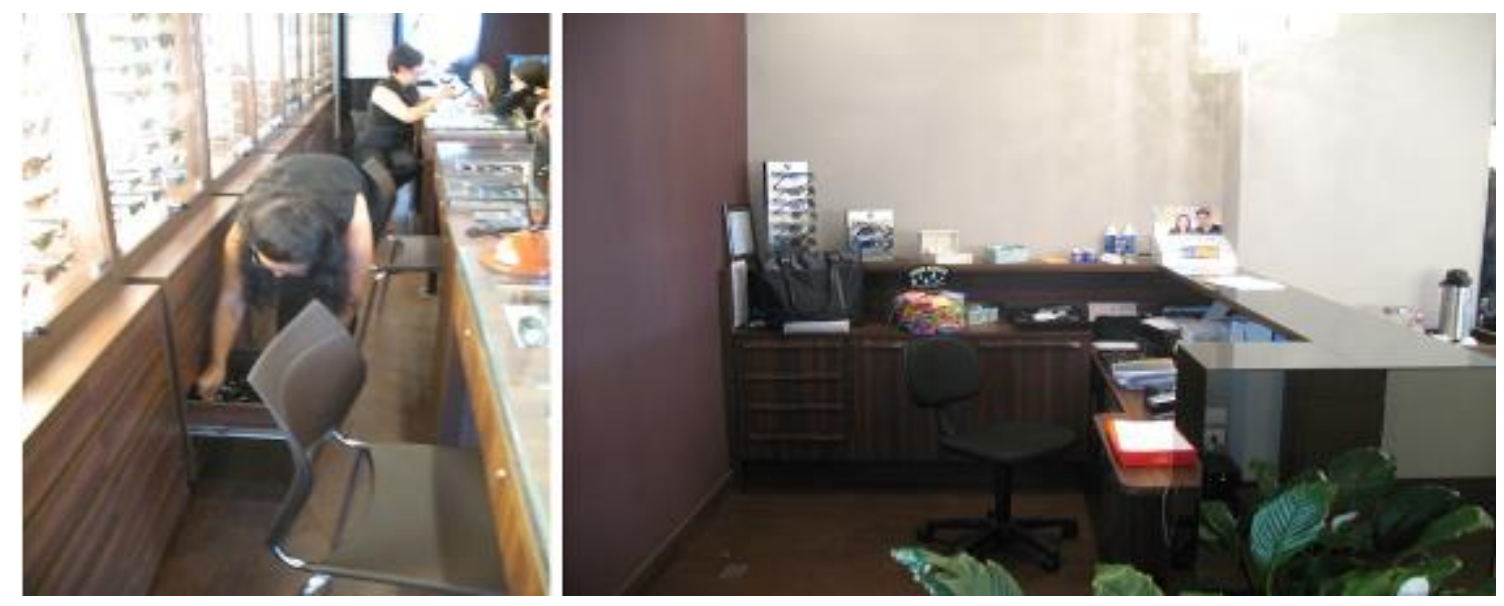

Fonte: Pesquisadores.

Posto de Trabalho 4 (Figuras 8 e 10): De forma geral, a avaliação é positiva, confirmando a visão da usuária, exceto pelo fato de a mesa estar baixa $(\mathrm{h}=70 \mathrm{~cm}) \mathrm{em}$ relação à medida de referência, que é igual à 73,70 a $76,20 \mathrm{~cm}$, e baixa também em relação à cadeira, causando um descompasso nessa relação. A cadeira, por sua vez, está alta, acima dos $43,2 \mathrm{~cm}$ recomendados. A altura do espaço para as pernas fíca prejudicado. O caso, porém, não é crítico, uma vez que a cadeira deste posto de trabalho é de altura regulável e o intervalo que ela apresenta pode compensar as diferenças detectadas. A caixa não a regulava por falta de orientação, caso já sanado.

O posto 1, tanto pelos problemas em si, quanto pelo tempo de permanência em seu uso, apresenta as maiores dificuldades. Em comparação a trabalhos em escritórios, as vendedoras e a gerente têm a vantagem de ter atividades bastante dinâmicas. Conforme a Norma Regulamentadora 17, a alternância das posturas é saudável, "pois permite que os músculos recebam seus nutrientes e não fiquem fatigados." (BRASIL, Ministério do Trabalho e Emprego, 2002). 


\section{DIÁGNOSTICO E RECOMENDAÇÕES}

Para a elaboração do diagnóstico, utilizou-se a classificação proposta por Moraes e Mont'Alvão (2003) para os problemas ergonômicos do sistema homem-tarefa-máquina. O diagnóstico permitiu elaborar diretrizes que contribuam para melhorias no ambiente estudado e suporte de novos projetos dessa natureza. A Tabela 4 expõe os conceitos relativos à natureza dos problemas encontrados.

Tabela 4: Categorização de problemas segundo Moraes e Mont’Alvão (2003), apenas com os três tipos de problemas encontrados.

\begin{tabular}{|c|c|}
\hline PROBLEMAS & CARACTERIZAÇÃO \\
\hline \hline INTERFACIAIS & $\begin{array}{c}\text { Posturas prejudiciais resultante de inadequaç̃os do campo de visão/tomada } \\
\text { de informaços, do envoltório acional/alcances, do posicionamento de } \\
\text { componentes comunicacionais, com prejuízos para os sistemas muscular e } \\
\text { esquelético. }\end{array}$ \\
\hline \hline $\begin{array}{c}\text { ESPACIAIS / ARQUITETURAIS } \\
\text { DE INTERIORES }\end{array}$ & $\begin{array}{c}\text { Deficiência de fluxo, circulação, isolamento, má aeração, insolação, } \\
\text { iluminação natural, isolamento acústico, térmico, radioativo, em função dos } \\
\text { acabamentos empregados. } \\
\text { Falta de otimização luminosa, da cor, da ambiência gráfica, do paisagismo. }\end{array}$ \\
\hline \hline FISICO-AMBIENTAIS & $\begin{array}{c}\text { Temperatura, ruído, iluminação, vibração, radiação, acima ou abaixo dos } \\
\text { níveis recomendados nas normas regulamentadoras. }\end{array}$ \\
\hline
\end{tabular}

Fonte: Moraes e Mont'Alvão (2003), adaptação gráfica pesquisadores.

A tabela 5 relaciona o problema aos métodos aplicados para o diagnóstico e às recomendações.

Tabela 5: Síntese do diagnóstico com recomendações.

\begin{tabular}{|c|c|c|}
\hline PROBLEMAS & MÉTODOS & RECOMENDAÇÕES \\
\hline $\begin{array}{l}\text { (1) Painel de óculos e } \\
\text { relógios com } \\
\text { iluminação muito } \\
\text { intensa, } \\
\text { ofuscante. }\end{array}$ & $\begin{array}{l}\text { Entrevistas } \\
\text { Observações } \\
\text { Walkthrough }\end{array}$ & $\begin{array}{l}\text { - Troca das lâmpadas fluorescentes comuns por lâmpadas } \\
\text { fluorescentes dimerizáveis. } \\
\text { Instalar película sobre o painel de acrílico, no tom champagne, } \\
\text { atenuando assim a intensidade luminosa. }\end{array}$ \\
\hline $\begin{array}{l}\text { Posto 3: Largura } \\
\text { insuficiente dos } \\
\text { corredores. }\end{array}$ & $\begin{array}{l}\text { Entrevistas } \\
\text { Observações } \\
\text { Avaliação } \\
\text { Antropométrica }\end{array}$ & $\begin{array}{l}\text { - Não há como ampliar a circulação sem efetiva troca de } \\
\text { mobiliário. }\end{array}$ \\
\hline 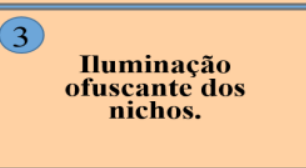 & $\begin{array}{l}\text { Entrevistas } \\
\text { Observações }\end{array}$ & $\begin{array}{l}\text { - A iluminação, feita por fita LED, está instalada com o fluxo } \\
\text { luminoso voltado para baixo. Se instalada com o fluxo } \\
\text { luminoso voltado para o fundo do móvel, não ofuscará os } \\
\text { olhos dos usuários, e alcançará melhor desempenho, } \\
\text { iluminando todo o interior do nicho, e não somente sua borda. }\end{array}$ \\
\hline $\begin{array}{c}\text { (4) } \begin{array}{c}\text { Iluminação } \\
\text { natural em } \\
\text { excesso em } \\
\text { alguns horários. }\end{array} \\
\end{array}$ & $\begin{array}{l}\text { Entrevistas } \\
\text { Observações }\end{array}$ & - Instalação de um toldo, em frente à loja. \\
\hline $\begin{array}{c}\text { Painel com a } \\
\text { sinalização da loja, } \\
\text { com retro } \\
\text { iluminação } \\
\text { ofuscante. }\end{array}$ & $\begin{array}{l}\text { Entrevistas } \\
\text { Observações } \\
\text { Walkthrough }\end{array}$ & $\begin{array}{l}\text { - Troca das lâmpadas fluorescentes comuns por lâmpadas } \\
\text { fluorescentes dimerizáveis. }\end{array}$ \\
\hline $\begin{array}{l}6 \\
\text { Inadequações do } \\
\text { Posto de Trabalho 1: } \\
\text { Mesas muito altas, } \\
\text { cadeiras } \\
\text { relativamente altas. }\end{array}$ & $\begin{array}{l}\text { Entrevistas } \\
\text { Observaçôes } \\
\text { Walkthrough } \\
\text { Avaliação } \\
\text { Antropométrica }\end{array}$ & $\begin{array}{l}\text { - Substituição das mesas, a serem dimensionadas de acordo } \\
\text { com os parâmetros indicados. } \\
\text { Providenciar um apoio para os pés da vendedora de menor } \\
\text { estatura. } \\
\text { - Substituir as cadeiras existentes (apenas dos funcionários) } \\
\text { por cadeiras de altura regulável. }\end{array}$ \\
\hline
\end{tabular}




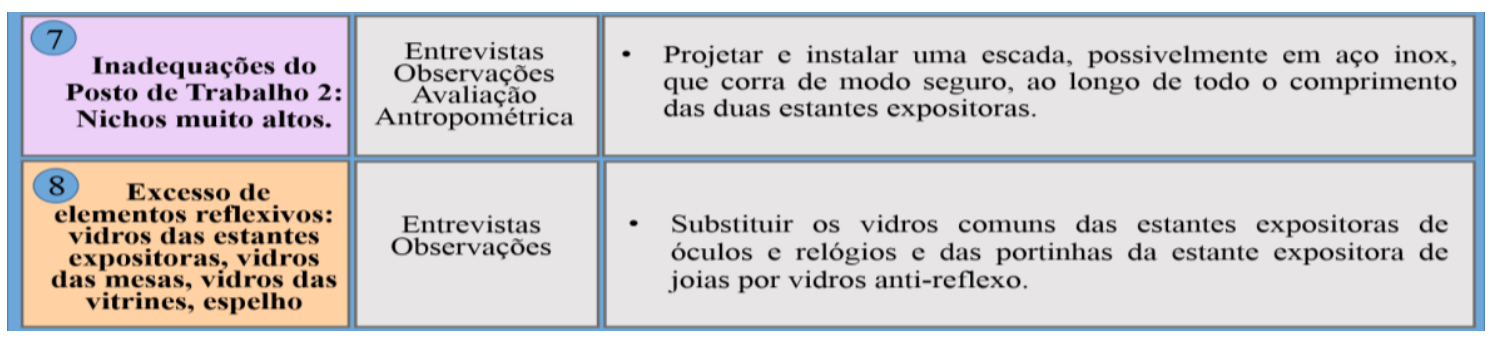

Fonte: Pesquisadores.

\section{CONSIDERAÇÕES FINAIS}

Foi de suma importância a abordagem ergonômica e a contribuição dos métodos de Avaliação Pós-Ocupação, que proporcionaram o entendimento do ambiente, evidenciando situações conflitantes que costumam passar despercebidas, mas que, com a pesquisa criteriosa, revelou aspectos a serem aprimorados, melhorando as condições de trabalho e o desempenho das tarefas. As simulações proporcionaram um raciocínio sobre o conforto e bem-estar dos usuários, avaliando as posturas dos trabalhadores durante o exercício das atividades e ainda na vivência do local. Constatou-se problemas relacionados, sobretudo, à altura dos móveis e dimensionamento das circulações, dificultando o alcance de produtos, causando constrangimentos. Foram ainda, identificadas disfunções na iluminação. Espera-se que o estudo realizado e as recomendações sugeridas possam contribuir, não apenas para a melhoria do ambiente avaliado, mas, também, de outros projetos de comercio de joias, reduzindo o desconforto e prováveis problemas de saúde dos trabalhadores.

\section{REFERÊNCIAS}

BAKER, Julie et al. The influence of multiple store environment cues on perceived merchandise value and patronage intentions. Journal of Marketing. v. 66. p. 120-141, 2002.

BRASIL. Manual de aplicação da norma regulamentadora $n^{\circ}$ 17. Brasília, DF: Ministério do Trabalho e Emprego, 2002. 101 p.

CBO - Classificação Brasileira de Ocupações. Disponível em <http://www.mtecbo.gov.br/> acesso em novembro de 2013.

GUÉRIN, François et al. Compreender o trabalho para transformá-lo: a prática da ergonomia. Tradução Giliane M. J. Ingratta, Marcos Maffei. São Paulo: Blucher, Fundação Vanzolini, 2001.

KOTLER, Philip. Atmospherics as a marketing tool. Journal of Retailing. v. 49, p.48-64, 19731974.

MORAES, A. de; MONT'ALVÃO, C. Ergonomia, Conceitos e Aplicações. Rio de Janeiro: iUsEr, 2003. $3^{\mathrm{a}} \mathrm{ed}$.

OKAMOTO, Jun. Percepção Ambiental e Comportamento. Visão holística da Percepção Ambiental na Arquitetura e na Comunicação. São Paulo: Editora Mackenzie, 2002.

PANERO, Julius; e ZELNIK, Martin. Dimensionamento Humano para Espaços Interiores. Barcelona: Editorial Gustavo Gili, 2002. Tradução: Anita Regina Di Marco. $1^{\text {a }}$ edição, $5^{\text {a }}$ impressão, 2010.

RHEINGANTZ, P. Aplicação do Modelo de Análise Hierárquica COPPETEC-Cosenza na Avaliação do Desempenho de Edifícios de Escritório. Rio de Janeiro, 2000. Tese (Doutorado em Engenharia de Produção) - COPPE, UFRJ. 